In the case of children undergoing preliminary skingrafting for burns or scalds, intubation is rarely necessary. At the Fleming Memorial Hospital for Children, Newcastle upon Tyne, such cases are given "nepenthe" intramuscularly or orally two or three hours before operation, and a blood transfusion is set up; apart from the nepenthe, no further sedation is given unless the child is exceptionally apprehensive. During the operation a light anaesthetic with nitrous oxide and oxygen plus a minimal amount of halothane given intermittently is all that is required. Post-operative recovery is extremely rapid, so that the problems of aftercare and feeding are made much easier from the nursing point of view.-I am, etc.,

Newcastle upon Tyne 3.

\section{Philip Ayre.}

\section{Toxicity of Methaqualone}

SIR,-A statement to the effect that serious toxic effects have not been reported for methaqualone appeared in your "To-day's Drugs" section (January 12, p. 107). It should be noted, however, that a record of toxicity from this drug appears in the July, 1962, issue of the Registry on Blood Dyscrasias of the American Medical Association Council on Drugs.

The Registry lists one case of aplastic anaemia with pancytopenia due to methaqualone. In addition there are listed two cases of thrombocytopenia due to ethinamate.-I am, etc.,

Memorial Hospital of Long Beach,

Long Beach, California, U.S.A. George X. TRIMBLE.

\section{Pulmonary Hypertension after Pregnancy}

SIR,-It is unfortunate that the second leader in the redesigned Journal (January 5, p. 3) on "Pulmonary Hypertension after Pregnancy" should omit to mention an important cause of this condition. The article rightly emphasizes the mechanism and diagnostic features of thrombo-embolism, but it fails to indicate that following pregnancy, whether full-term, abortive, or molar, the thrombo-emboli may consist of or may contain trophoblastic tissue. ${ }^{1-5}$ This embolic trophoblastic tissue may be choriocarcinoma or histologically benign hydatidiform mole, or an intermediate form. Any of these neoplastic forms if left untreated in the pulmonary arteries can kill the patient.

Since the amount of trophoblastic tissue in a particular pulmonary thrombus may be very small it can be missed at necropsy. The absence of a typical tumour mass in the pelvis may add to the diagnostic mimicry of ordinary thrombo-embolism. The source of the emboli in these cases is trophoblastic tissue lying in the uterus or in pelvic veins, where its presence may also be hidden by thrombus. Such patients may have few if any gynaecological symptoms, pelvic examination may show no abnormality and uterine curettings are normal.

Clinical and radiological examination of the cardiopulmonary system will not distinguish these two forms of thrombo-embolism, nor will the most sophisticated cardio-respiratory function studies. This is not surprising since the functional disturbance is identical in both forms. The distinction between the two forms is important therapeutically. Those due to trophoblastic disease do not respond to anticoagulant therapy alone, but they do respond to specific cytotoxic therapy.

The trophoblastic cases can only be recognized by testing for chorionic gonadotrophin. This can be done initially by the routine pregnancy tests, and if pregnancy has been excluded a valid positive test establishes the

presence of trophoblastic disease. If negative, trophoblastic disease is still not excluded, since the amount of hormone being produced may be insufficient to give a positive test. In these cases sensitive quantitative tests for chorionic gonadotrophin must be performed. Similar sensitive and quantitative assays are essential for the proper management and treatment of all forms of abnormal trophoblastic proliferation. It is not known how frequently the trophoblastic form of post-pregnancy thrombo-embolism occurs, but, like other things, it will only be found if it is looked for.-I am, etc.,

$$
\begin{gathered}
\text { Department of Medicine, } \\
\text { Charing Cross Hospita } \\
\text { Medical School, } \\
\text { Fulham Hospital, } \\
\text { London W.6. }
\end{gathered}
$$

\section{K. D. Bagshawe.}

\section{REFERENCES}

Bardawil, W. A., and Toy, B. L., Ann. N.Y. Acad. Sci., 1959. 80. 197.

McKeown, F., Ulster med. J., 1949, 18. 59

Bagshawe, K."D., and Brookes, W. D. W., Lancet, 1959, 1, 653. Lipp, R. G., Kindschi, J. D., and Schmitz, R., Amer. J. Obstet. Gynec., 1962, 83, i644.

- Ober, W. B., Ann. N.Y. Acad. Sci., 1959, 80, 1.

\section{D.N.A. and the Chromosomes}

SIR,- - It is with great interest that I have read papers by Drs. N. B. Atkin and B. M. Richards concerning the D.N.A. content of cervical carcinoma. I am afraid, however, that their latest preliminary report (December 1 , p. 1445) will be a source of confusion with respect to the karyology of cervical cancer.

The terms "diploid" and "tetraploid" as used in this article are not consistent in meaning with previous, comparable studies based on precise chromosome analysis. To my knowledge there is no microspectrophotometric technique which allows the accurate determination of chromosome number, particularly when working with old histological sections as the authors describe. In cancerous cells there is only a close relationship between D.N.A. measurements and chromosome number. ${ }^{1}$ Based on my own observations, I will estimate that less than $10 \%$ of the tumours in the diploid class actually have exactly 46 chromosomes. Yet it is the clear implication of the article, as evidenced by the editorial comment in the same issue, that these tumours are diploid; that they have 46 chromosomes.

It is to be hoped that in the future the author will avoid the term "diploid" when referring to those cancerous cells whose D.N.A. content lies in the range of normal cells. I have also noted that the conclusions of this preliminary report are contrary to De's observations, ${ }^{2}$ which were based on chromosome analysis. -I am, etc.,

$$
\begin{aligned}
& \text { Stanford Medical Center, } \\
& \text { Palo Alto, California, U.S.A. } \\
& \text { References } \\
& 1 \text { Ojima, Y., Inui, N., and Takayama, S., Gann, 1962, 53, } 123 . \\
& 2 \text { De, N., Brit. J. Cancer, 1961, 15, 54. }
\end{aligned}
$$

\section{Ataxic Neurological Syndrome}

SiR,-As Dr. D. R. W. Haddock and his colleagues point out in their account (December 1, p. 1442) of an ataxic syndrome in Tanganyika, prevailing conditions in East Africa may lead to further cases and should be carefully watched for. Such multiple neuropathies of obscure aetiology are probably more common than is realized. The writer reported ${ }^{1}$ an outbreak of pellagra in Lake Province, Tanganyika, with evidence of multiple deficiencies of the vitamin B complex. One case besides having an atrophic glossitis, styes, and dyssebacea (see 